\title{
La experiencia escolar como experiencia de clase: fronteras morales, estigmas y resistencias
}

\author{
MARÍA CRISTINA BAYÓN Y GONZALO A. SARAVÍ
}

MARÍA CRISTINA BAYÓN

Universidad Nacional Autónoma de México, Instituto de Investigaciones Sociales,

Ciudad de México, México cristina.bayon@sociales.unam.mx

GonZALO A. SARAVÍ

Centro de Investigaciones y Estudios Superiores en Antropología SocialCiudad de México, México gsaravi@ciesas.edu.mx
Las dimensiones morales y simbólicas juegan un papel central en la producción y legitimación de la desigualdad, y en Latinoamérica han sido poco exploradas. Este artículo pretende contribuir a cubrir ese vacío con el análisis de la experiencia escolar de adolescentes de clases subalternas, las valoraciones, estigmas y clasificaciones en torno a sus trayectorias educativas, logros y escuelas a las que asisten. Reflexionamos acerca del andamiaje cultural y moral que legitima y consolida las desigualdades de clase en México y sus implicaciones en la experiencia social y subjetiva de los individuos.

PalABras Clave: desigualdad social, experiencia de clase, sociología de la educación, fronteras simbólicas, sectores populares

School Experience as a Class Experience: Moral Boundaries, Stigma and Resistance

Moral and symbolic dimensions play a key role in the production and legitimation of inequality, and they remain under-explored in Latin America. This article makes a contribution for filling this gap by analyzing the school experience of lower social classes adolescents as well as the values, stigma and classifications constructed on their educational trajectories, achievements and schools. The discussion focuses on the cultural and moral framework that legitimizes and consolidates class inequalities in Mexico, and its implications on the social and subjective experience of individuals.

KEYWORDS: social inequality, class experience, sociology of education, symbolic boundaries, working class 


\section{Introducción ${ }^{1}$}

as desigualdades de clase tienen un fundamento estructural en la distribu-

ción desigual de los recursos de una sociedad, pero expresan y son posibles a partir de relaciones de poder mediadas por la cultura (Tilly, 2000). En otros términos, el privilegio de unos y la privación de otros requiere un soporte cultural que los legitime socialmente, que permita lidiar de manera subjetiva con esas disparidades y regule las interacciones entre miembros de clases antagónicas. De manera creciente, en las ciencias sociales se ha reconocido el papel de las dimensiones morales y simbólicas en la persistencia y profundización de la desigualdad, y en la resistencia de las clases subalternas. Junto a las bases materiales, asociadas a la distribución inequitativa de recursos y oportunidades, los modos en que nos relacionamos, tratamos y representamos a los "otros" son esenciales para explicar por qué la desigualdad es socialmente aceptada, legitimada y naturalizada.

A pesar de que Latinoamérica es una de las regiones más desiguales del mundo y con alta tolerancia social a la desigualdad (Lübker, 2004; Álvarez, 2014), las dimensiones morales y simbólicas aún constituyen un campo poco explorado en los estudios sobre el tema (Reygadas, 2015; Saraví, 2015). Esto es válido en particular en el caso de México, donde el modelo neoliberal ha tenido una continuidad marcada, que ha exacerbado los altos y arraigados niveles de desigualdad social que caracterizan su historia reciente (Bayón, 2009). ${ }^{2}$ En contextos como éste, en el

1 Este artículo es producto del proyecto de investigación "Espacios de pertenencia escolar" (EPES), financiado por el Fondo Sectorial de Investigación para el Desarrollo Social, de la Secretaría de Desarrollo Social y el Consejo Nacional de Ciencia y Tecnología (2016-1-276380), <https://www. proyectoepes.com>.

2 En 2014, el coeficiente de Gini para la distribución de los ingresos de los hogares era de 0.507, muy por encima del promedio de los países de la Organización para la Cooperación y el Desarrollo Económicos, de 0.33, y entre los más altos de Latinoamérica (CEPAL, 2017). 
que la profundidad de las brechas sociales hace que vivamos en una suerte de sociedades paralelas, resulta relevante preguntarse cuáles son las explicaciones dominantes y socialmente aceptadas sobre la suerte de los más desfavorecidos. ¿Cómo lidian y procesan en la subjetividad esas representaciones socialmente construidas sobre ellos? ¿En qué medida estos discursos contribuyen a legitimar los privilegios de los más ricos, y por lo tanto, a justificar la desigualdad y la disciplina que se impone a los sectores subalternos?

Para responder a estas interrogantes, nos centramos en la experiencia escolar como experiencia subjetiva de clase entre adolescentes de sectores populares que cursan la educación media superior en México. A partir de la exploración de las valoraciones, estigmas y clasificaciones que se construyen en torno a estos estudiantes, sus trayectorias y logros educativos, y las escuelas a las que asisten, analizamos y reflexionamos sobre el andamiaje cultural que legitima y consolida las desigualdades de clase. La discusión no se inserta de manera estricta en el debate especializado acerca de la desigualdad educativa, sino que toma la experiencia escolar como expresión y escenario en el que se ponen en juego dimensiones morales y simbólicas de la desigualdad de clase.

La elección de este espacio, no obstante, no es fortuita. La educación ha estado en el centro de los debates sobre la desigualdad. Desde varias perspectivas, con sus matices internos, ha sido concebida como el fundamento último para alcanzar la anhelada igualdad de oportunidades, o bien, como el mecanismo de reproducción de la desigualdad de posiciones por excelencia.

En México, según datos oficiales del Consejo Nacional de Evaluación de la Política de Desarrollo Social (Coneval, 2014), 60.3\% de los adolescentes de 12 a 17 años de edad vive en hogares pobres por ingresos y otro $23.1 \%$ es vulnerable por otras carencias sociales. Sin embargo, en el transcurso de las últimas décadas, el sistema educativo ha tenido una expansión significativa y ha permitido de manera paulatina el acceso de estos sectores a niveles de formación más altos. ${ }^{3}$ Así, por un lado, la escuela parece haber comenzado un proceso de integración de los sectores populares, conducente a un mayor grado de igualdad; pero por el otro, el sistema educativo se ve permeado cada vez más por desigualdades, ya sea entre regiones y localidades (Backhoff et al., 2007), entre tipos de escuelas (Backhoff et al., 2007; Blanco, 2011; Blanco, Solís y Robles, 2014) o incluso entre turnos de un mismo plantel (Cárdenas, 2011). Es decir, la educación deja de ser un bien raro, privilegio de una minoría, y se segmenta en el interior.

La mayoría de los estudios sobre desigualdad educativa en México se han concentrado en las diferencias de acceso y permanencia entre contextos o sectores sociales, y en años más recientes en las disparidades en el aprovechamiento o rendimiento de los alumnos. En todos los casos, como señala Aguilar (2013), el predominio de los estudios cuantitativos, y de carácter macro y descriptivo, ha sido casi absoluto. ${ }^{4}$ En oposición, son casi inexistentes los estudios que analicen las desigualdades educativas a partir de la experiencia escolar de los estudiantes, lo cual requiere de una estrategia metodológica cualitativa y etnográfica. De por sí, los estudios sobre la experiencia escolar son recientes y aún escasos en México — como los reunidos por Guzmán y Saucedo (2015) y Weiss (2012) — y sólo algunos se refieren en específico a la experiencia de la desigualdad. La

Para el ciclo escolar 2014-2015, la cobertura neta en educación media superior, es decir, el porcentaje de adolescentes de 15 a 17 años de edad que estudia en este nivel, fue de $57 \%$ (INEE, 2016)

4 Más allá de la observación de Aguilar, en los últimos años, estudios cuantitativos, como los citados en el párrafo anterior, buscan ir más allá de la descripción para encontrar asociaciones entre factores escolares y extraescolares con dimensiones distintas de la desigualdad educativa, en especial en calidad o continuidad. 
contribución de este artículo reside precisamente en echar luz sobre el sello que imprime la condición de clase a la experiencia escolar.

\section{Legitimar la desigualdad: clase, estigma y meritocracia}

La implementación y posterior consolidación de las reformas neoliberales que se expandieron con la globalización a partir de la década de 1980 dieron lugar a una nueva cuestión social. La pobreza se institucionalizó, la vulnerabilidad se expandió como condición de vida de amplios sectores y la exclusión emergió como el destino final de la acumulación de desventajas entre los más desfavorecidos. En años recientes hemos sido testigos de una ampliación dramática de la desigualdad social que genera verdaderos abismos entre clases sociales. Como contraparte clave para su instrumentación, las reformas neoliberales han tenido la expansión y penetración social de un discurso neoliberal como modo de explicación dominante de los problemas sociales. Es decir, la emergencia de una nueva cuestión social se ha acompañado de una lectura particular e interpretación social y simbólica de los fenómenos que la caracterizan, en especial la pobreza, la exclusión y las desigualdades de clase. En este discurso, el individuo, sus capacidades y cualidades morales se ponen en el centro de toda explicación posible.

En efecto, para el discurso neoliberal hegemónico, la condición de clase se reduce a una cuestión de carácter y esfuerzo, sin relación con desigualdades estructurales o con la distribución de recursos en la sociedad (Sayer, 2005). La desigualdad "emerge" como el resultado de elecciones y atributos personales, y la inequidad en la distribución de recursos materiales y culturales se explica como el resultado inevitable, casi natural, de las "deficiencias" propias de ciertos sectores, a la postre, los pobres y desfavorecidos. En este contexto, el "racismo de clase" (Bourdieu, 2002) ha resurgido con particular virulencia mediante un discurso criminalizador y despectivo hacia los grupos de menores ingresos, encasillados en estereotipos que los presentan como inferiores o deficitarios, ridículos o desagradables, generadores de miedo y disgusto, o incorregibles. Se trata de un sistema de inscripción y clasificación que presenta a los sectores populares con atributos y valores negativos, adscritos y esenciales, que los descalifican y clasifican como inmorales y criminales (Skeggs, 1997).

La clase no es sólo un concepto sociológico o una categoría teórica para ubicar segmentos poblacionales en el campo social, es una experiencia vivida. Se encarna con intensidad, permea nuestra experiencia y sentido de nosotros mismos, afecta la autovaloración y la autoestima, y permite entender cómo los grupos se definen en contraste con otros por medio de límites simbólicos (Lamont y Molnár, 2002). La construcción del otro y la otredad se ligan a la dimensión moral de la experiencia de clase, en otros términos, nuestra experiencia cotidiana de cómo la gente trata y valora al otro. La clase es clave en nuestras experiencias biográficas, no sólo por las diferencias en riqueza material y seguridad económica que la determinan, sino porque afecta nuestro acceso a objetos, relaciones, experiencias y prácticas que valoramos, por lo tanto, nuestras oportunidades de vivir una vida plena y gratificante. Impacta, además, en el modo en que los demás nos valoran y responden, por lo cual tiene también influencia directa sobre nuestra autoestima. Como señala Sayer (2005), los individuos dependen de otros no sólo para obtener apoyo material, sino porque necesitan un reconocimiento continuo, aprobación y confianza, cuya ausencia genera angustia, vergüenza y autodesprecio. Así, el reconocimiento, el respeto y la valoración de otros son tan esenciales para el bienestar como la satisfacción de las necesidades materiales. La falta de reconocimiento incluye privaciones tanto materiales como simbólicas. 


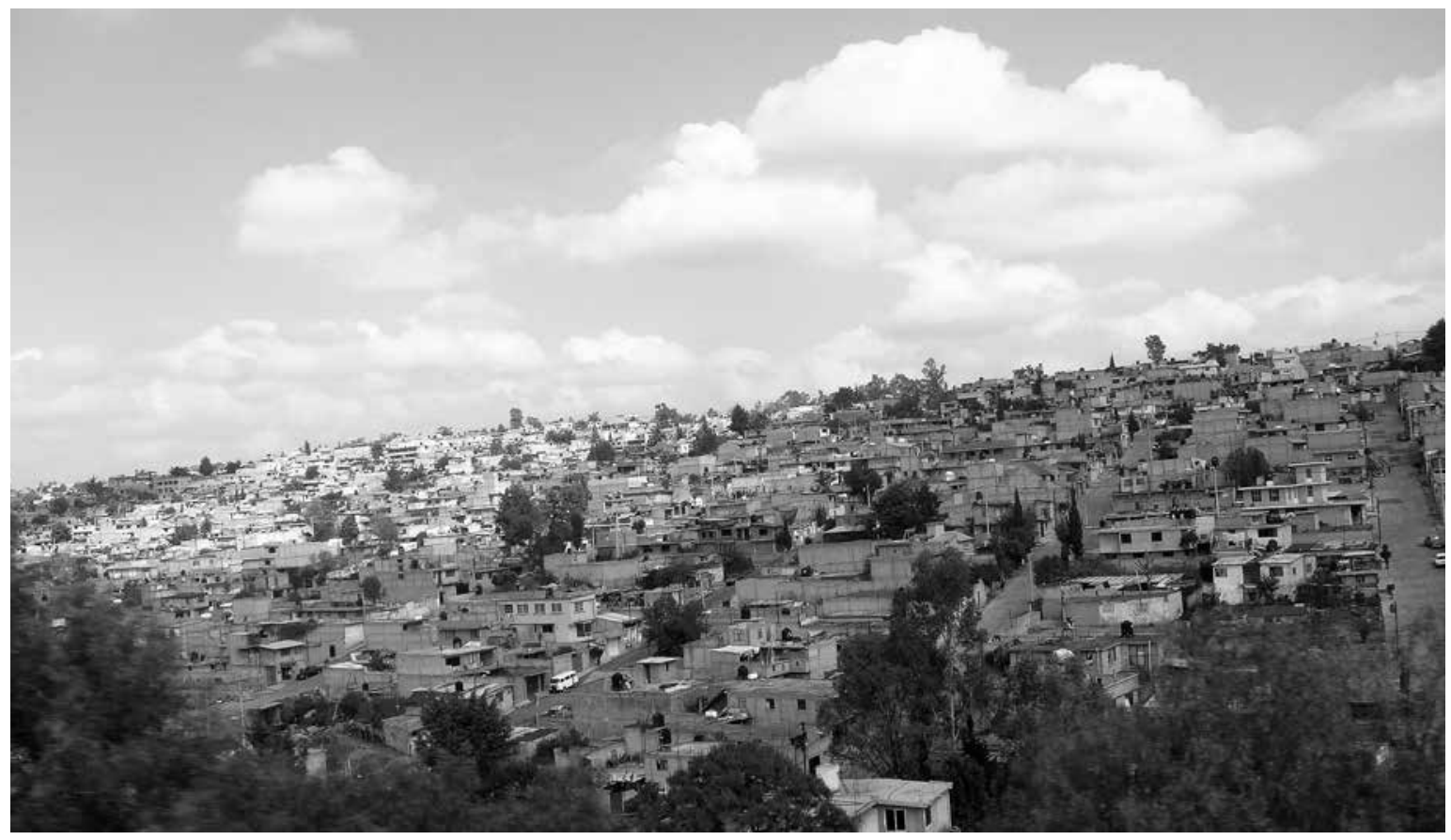

Lucy Nieto • La Quebrada, Cuautitlán, Estado de México, marzo de 2009.

En este sentido, nos interesa destacar que la estigmatización de los grupos más desfavorecidos y sus espacios - barrios o colonias, áreas de diversión y consumo, clínicas de salud o escuelas - opera como una forma de gobernanza que legitima la reproducción y consolidación de las desigualdades y las injusticias sociales. Bourdieu destaca que, en las luchas por el sentido del mundo social, lo que está en juego es el poder sobre los esquemas y sistemas clasificatorios que constituyen las bases de las representaciones de los grupos, y en consecuencia, de su movilización o desmovilización (2002: 490). En otras palabras, las clasificaciones no sólo describen el mundo, sino que tienen consecuencias operativas en la definición de las posibilidades de acción y delimitación del propio sentido de agencia de los sujetos. La mayoría de las representaciones sobre los sectores populares, en particular en tiempos neoliberales, devalúan y desprecian sus capitales escasos, sus comportamientos y preferencias, sus estilos y formas de vida, y brindan así un soporte clave para la legitimación social y moral de la desigualdad, que favorece su producción y reproducción. En efecto, la clasificación en categorías ordenadas por jerarquías es una estrategia esencial en la construcción de la desigualdad.

Estos sistemas de clasificación, en tanto relaciones de poder, no sólo representan la mirada del otro superior en la jerarquía, sino que afectan los procesos de subjetivación. Como han señalado otros autores, la estrategia discursiva del estereotipo no supone sólo la fabricación de una imagen falsa sobre los sujetos estigmatizados, sino que posee una fuerza de subjetivación (Bhabha, 1983; Tyler, 2013). Es decir, los sujetos estigmatizados no sólo padecen el estigma, sino que éste moldea y condiciona la construcción identitaria de sí mismos, así como la autoestima y valoración social.

La escuela constituye un espacio privilegiado para analizar estas dimensiones morales de la clase 
y sus efectos en la legitimación de la desigualdad. Como señalamos, el incremento en el acceso de los sectores desfavorecidos al sistema educativo se ha acompañado de una creciente segmentación y estratificación escolar (Blanco, 2014; Saraví, 2015). Junto a las desigualdades en infraestructura, recursos pedagógicos y desempeño escolar, una dimensión básica para entender la desigualdad se refiere a las imágenes y representaciones sociales que se construyen sobre las escuelas a las que asiste cada clase social, sus trayectorias y logros educativos, incluso acerca de las cualidades personales de los estudiantes. Como advierte Reay (2017), la escuela constituye un medio poderoso para legitimar tanto el elitismo como la exclusión.

\section{Metodología}

La información empírica que sustenta este análisis proviene del trabajo etnográfico que realizamos en dos escuelas públicas de nivel medio superior a las que asisten en su mayoría jóvenes provenientes de sectores populares. Una está en la Ciudad de México y pertenece al subsistema del Colegio Nacional de Educación Profesional Técnica (Conalep), correspondiente a la modalidad de bachillerato tecnológico. La otra es una escuela de bachillerato general dependiente de la Secretaria de Educación Pública del Estado de México, ubicada en el municipio de Nezahualcóyotl, en la periferia oriente de la ciudad. La elección de las escuelas respondió al perfil técnico de una y a la localización de la otra, lo cual nos permitía anticipar la condición de clase mayoritaria de sus alumnos. En ambas instituciones se realizaron entrevistas semiestructuradas -24 con estudiantes y diez con docentes—, un grupo focal en cada escuela, en los que participaron otros 11 jóvenes, observaciones y charlas informales con otros miembros de la comunidad.

Todos los estudiantes cursaban el segundo semestre y tenían entre 15 y 18 años de edad al momento del trabajo de campo. Se distribuyeron en proporciones similares de varones y mujeres, 17 y 18 , respectivamente, y entre los turnos matutino y vespertino, 19 y 16. Los autores hicimos todas las entrevistas en las instalaciones escolares, entre mayo y octubre de 2017. Se grabaron y transcribieron íntegras, y después se codificaron y analizaron con el software NVivo 11 para análisis cualitativo. Para preservar la confidencialidad de la información y el anonimato de los participantes, sus nombres y el de las escuelas han sido reemplazados por otros ficticios.

\section{Dimensiones morales de clase en la experiencia escolar}

\section{LA MERITOCRACIA COMO MECANISMO} DE JERARQUIZACIÓN SOCIAL

En la Ciudad de México y su área metropolitana, el proceso de selección para ingresar a una escuela de nivel medio superior en el sector público se basa en un examen general, aplicado por la Comisión Metropolitana de Instituciones Públicas de Educación Media Superior (Comipems). Todos los aspirantes deben seleccionar máximo 20 escuelas a las que desearían ingresar, en orden de preferencia. De acuerdo con el resultado obtenido en el examen y la demanda existente - las escuelas más demandadas exigen un puntaje más alto-, los estudiantes acceden o no a la escuela de su elección. Así, el lugar que ocupa la escuela a la que en efecto ingresan constituye para los estudiantes un indicador de las capacidades propias, incluso del valor social de sí mismos:

Yo estaba súper nerviosa y la verdad no me sentía a gusto haciendo el examen. Y ya cuando salieron mis resultados, la verdad sí me puse muy triste, porque yo quería estar en el Politécnico. Entonces, cuando vi que había sacado $86 \ldots$ [se corta la voz, con angustia] y entonces yo me sentí: “iay, 
no! ¡Estoy muy burra!”, o cosas así. Porque, por ejemplo, todos mis amigos se quedaron en prepas de la UNAM o así, y yo aquí... [risas]. Entonces decía: "nooo, estoy bien tonta, por qué no estudié más”, o cosas así. Sí, me bajó mi autoestima mucho (Zule, 15 años de edad, bachillerato general, grupo focal GF-B01).

La mayoría de los estudiantes entrevistados en ambas escuelas había colocado entre sus primeras preferencias escuelas públicas muy demandadas y con más prestigio: las preparatorias y colegios de la Universidad Nacional Autónoma de México (UNAM) o del Instituto Politécnico Nacional (IPN). Esto es consistente con las estimaciones de Solís, Rodríguez y Brunet (2013), que señalan que tres de cada cuatro estudiantes - 76.8\% - que presentan el examen de Comipems en la Ciudad de México colocan escuelas de alta demanda en sus primeras dos opciones. Además del reconocimiento social, la preferencia por estas escuelas se debe a que facilitan el ingreso de sus alumnos a las licenciaturas de las instituciones de las que dependen. La elección de las escuelas, al menos de manera explícita, no tiene restricción alguna y el acceso a ellas por medio de un examen parece que depende sólo de las capacidades y méritos individuales. De este modo, las escuelas se constituyen en un termómetro de autovaloración y del valor social del sujeto. Los adolescentes entrevistados asumen el hecho de no haber sido aceptados para sus primeras opciones como una frustración y desvalorización individual, y como una representación simbólica de su lugar en la jerarquía social:

Entrevistador: Cuéntame, cuando te asignaron a esta escuela, ¿qué fue lo que pensaste?

Lucy: No me sentí... es que yo, así como que... me dije: "pues yo no quiero ni quedarme así, ni en una ni en otra, sino quiero la que realmente merezca, en la que yo pueda merecerme". Entonces, cuando yo veo mi resultado, pues no me sentí mal ni me sentí triste ni nada, pero mi papá sí, como que... me dijo que hasta ahí iba a quedar, que ya no iba a lograr más cosas, y pues quieras o no, sí pega un poco oír todo eso siendo de tu padre, ¿no? (Lucy, 15 años de edad, bachillerato técnico, entrevista E-A01).

La imputación de responsabilidad a un individuo por procesos sociales externos a él, que se ocultan tras el discurso meritocrático, emerge con toda claridad en voz de sus víctimas. Lucy no sólo se resigna a no acceder a la escuela que eligió, sino que considera que por sus condiciones y capacidades "merece" la que le asignaron. En este proceso de selección de la escuela, las expectativas individuales de los estudiantes de sectores populares comienzan a emparejarse con las determinaciones sociales del destino de clase.

Aunque la selección de escuela se presenta como un proceso abierto, para muchos representa transitar hacia un destino socialmente preestablecido. La obtención de un puntaje determinado es una posibilidad más o menos accesible que depende de las capacidades individuales pero también de los contextos, circunstancias y condiciones en las que se sitúan los individuos (Ball et al., 2002). Sin embargo, los sentimientos que expresan los estudiantes al no alcanzar el resultado requerido revelan procesos de autodevaluación y autoculpabilización. Lo experimentan como un fracaso individual, una evidencia de deficiencias o limitaciones individuales; se sienten "tontos", "burros", "no merecedores", en comparación con quienes alcanzan el objetivo. Guzmán (2012) registró hallazgos similares en un estudio sobre aspirantes a la UNAM que no obtuvieron la calificación necesaria para ingresar a la licenciatura. Estos jóvenes experimentaron la misma frustración cuando no lograron entrar a un bachillerato dependiente de la misma casa de estudios, que les hubiera permitido transitar de manera directa a la universidad: "la primera respuesta y la más frecuente es la 
auto-culpabilización, esto es, atribuyen los resultados de manera individual a su falta de esfuerzo y dedicación" (2012: 159). Los problemas estructurales - un sistema escolar fragmentado que reproduce las desigualdades sociales y relega a quienes provienen de sectores más desfavorecidos a las escuelas menos demandadas y de menor estatus - se viven como fracasos individuales. Esta individualización de los problemas sociales, propia del discurso neoliberal hegemónico, tiene el doble efecto de erosionar la autoestima de los estudiantes más pobres e infravalorar sus credenciales futuras y carreras educativas por asistir a las escuelas que nadie elige:

Entrevistador (E): Y en su caso, ¿esta escuela fue la primera opción o no tanto?

Todos: ¡No, no!

Lola (L): Yo nada más puse siete opciones y ésta fue la quinta. Algunos nada más la pusieron por rellenar y muchos nos quedamos aquí [risas de todos].

Edu (ED): Para mí también fue la quinta, pero yo puse diez.

Zule (z): Yo puse cinco, ésta fue la tercera.

Perla: No, yo la puse como que de relleno... Así como que no me quedaba otra opción que ponerla [risas de todos]. De relleno...

E: ¿`Y tú?

Franco (F): Yo puse 25 y todas fueron de relleno, nada más cinco eran las que yo quería, todas las demás eran relleno, incluyendo ésta [risas].

E: ¿Y eso cómo les pega? ¿Les afecta en algo?

Z: Bueno, a mí no porque aquí estudió mi hermana, mi prima, parte de mis primas.

E: Pero en algo les debe haber afectado porque por algo pusieron otras primero.

Z: Bueno, sí, porque por ejemplo, yo quería el Poli y no quedé, entonces sí me puse muy triste.

L: Como que todos íbamos por Poli y UNAM.

ED: Así es cuando en la secundaria te toca hacer eso. Todos, todos ponen escuelas del Poli o de la UNAM.
F: Pocos son los que ponen escuelas como ésta como primera opción.

L: Como Bachos o como ésta. Al menos que ya sepas que no has estudiado, o no sepas adónde estás aspirando... [risas de todos].

ED: O Conaleps (Lola, 16 años de edad; Edu, 15 años de edad; Zule, 15 años de edad; Perla, 16 años de edad; Franco, 16 años de edad, bachillerato general, grupo focal GF-B01).

Los jóvenes se enfrentan de manera cotidiana a la falta de reconocimiento como estudiantes exitosos e individuos valiosos. El peor desempeño escolar se visualiza como una carencia personal, por ello les afecta tener que "dar la cara" a los demás (Guzmán, 2012). La falta de reconocimiento, observa Reay (2017), pone en evidencia la sinergia entre el mercado y el sistema educativo, que operan para ubicar a los sectores desfavorecidos en el escalón más bajo de una jerarquía de valor y respeto en ambas esferas: asistir a escuelas devaluadas en términos académicos supone no sólo ser vistos como "malos", sino como "estúpidos" o "burros", por lo que la vergüienza y la humillación de ser moralmente descalificados y despreciados están siempre presentes.

\section{ESTIGMAS ESCOLARES: LOS OTROS COMO INFERIORES}

Conscientes del lugar que ocupan en la estructura escolar y de cómo se posicionan ellos mismos en el ranking de escuelas, estos jóvenes enfrentan poderosos ataques a su persona y su identidad que provienen de asistir a escuelas que otros consideran de calidad insuficiente para gente inteligente. La experiencia escolar tiene repercusiones emocionales en su construcción identitaria, pues los obliga a lidiar con el sufrimiento de ser descalificados en sus cualidades individuales y resistir las amenazas que esto supone para su autoestima. Asistir a las 
escuelas que nadie elige, estigmatizadas por ser poco exigentes y muy "fáciles", por la orientación del plan de estudios, vocacional, por ejemplo, o por su localización, se inscribe en un proceso más amplio de falta de reconocimiento de los sectores más desfavorecidos. Así, el incremento del acceso de los sectores populares al sistema educativo, en escuelas socialmente devaluadas, constituye una experiencia paradigmática de inclusión desfavorable, una integración excluyente que expone la forma que adquiere su pertenencia social en contextos de alta desigualdad y fragmentación social (Bayón, 2015):

Luis (L): Bueno, es que aquí en México, no sé si haya visto, que aquí denigran mucho al Conalep.

Entrevistador (E): ¿Qué cosas denigran?

L: O sea, que odian mucho al Conalep, como que lo ven así, muy de burros, de que embarazan mucho a las muchachas y así. ¿Nunca ha visto?

E: ¿De dónde sacas eso?

L: De las redes sociales y de que todo el mundo dice eso. Allá, en Ecatepec, así decían. Decían que el Conalep es lo peor, que si te quedas ahí eras esto y lo otro.

E: ¿Y cuál es tu reacción frente a eso?

L: A mí se me hace mal, te hace sentir mal, porque como que se burlan de ti, empiezan a decir: "ay, vas a un Conalep, vas en un 'Nopalep”' [ríe]. Así le dicen (Luis, 15 años de edad, bachillerato técnico, entrevista E-A08).

El relato de Luis, como el de la mayoría de los estudiantes entrevistados, en particular en el bachillerato técnico, muestra no sólo un claro reconocimiento del estigma que pesa sobre sus escuelas, sino también de los atributos morales a partir de los cuales se construyen. En efecto, las imágenes negativas no se refieren sólo a aspectos académicos, sino también a comportamientos, estilos y prácticas moralmente censuradas y despreciadas, atribuidas al colectivo de las clases subalternas. A partir de un proceso meritocrático que parece depender sólo de las capacidades y esfuerzos individuales, los adolescentes de sectores populares son empujados a escuelas devaluadas y desprestigiadas por su calidad y los estratos sociales que asisten a ellas. La patologización de las clases populares se traslada a las escuelas a las que asiste. Este mecanismo circular desvaloriza de nuevo a los estudiantes y sus experiencias escolares (Reay, 2007; Sibley, 1995; Watt, 2006). La descalificación de los sectores populares y su desplazamiento hacia las instituciones educativas en las que por lo regular estudian tiene una expresión cruda y evidente en las denominaciones que reciben las escuelas, que aprovechan la fonética de ciertas palabras. Como Luis, muchos estudiantes del Conalep comentaron sobre los memes, expresiones de discriminación y burlas que circulan en espacios virtuales y en la vida cotidiana, que se refieren a sus escuelas como Nacolep o Nopalep, una combinación del nombre del sistema educativo con palabras con significados o connotaciones despectivas hacia los sectores populares — naco y nopal-, 5 una muestra clara del racismo de clase.

Casi todos los estudiantes entrevistados se refirieron con espontaneidad a los memes que circulan en las redes sociales sobre este tipo de escuelas y ejemplifican estereotipos discriminatorios, humillantes y peyorativos. Lo confirmamos con una indagación superficial en internet. Los memes hablan de estos planteles como centros de adolescentes embarazadas o madres solteras, muestran a las chicas como vulgares y promiscuas en sus relaciones con los varones, y a

5

Ambos términos tienen una fuerte carga despectiva, con frecuencia clasista y racista. Naco se utiliza para hacer referencia a alguien vulgar y de mal gusto en la forma de hablar y de vestir, de bajos recursos. El nopal es una planta cactácea, cuyos tallos y palas excretan mucílago cuando se cortan. Con el término se alude a alguien tonto —baboso-, poco inteligente, y también es una manera discriminatoria de llamar al campesinado mexicano. 


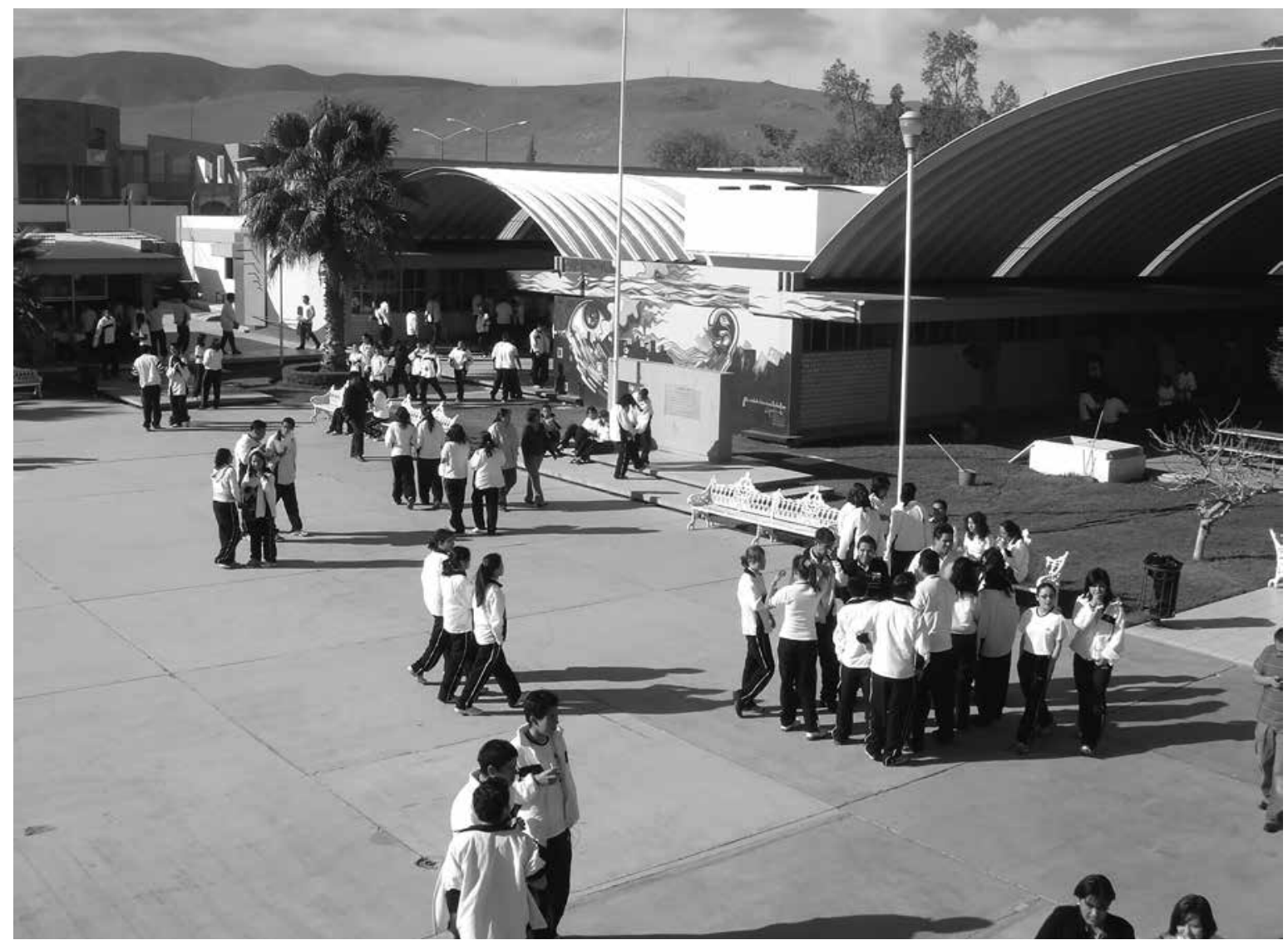

LUCY Nieto • Colegio de Bachilleres número 28 en San Luis Potosí, México, febrero de 2008.

ellos como poco inteligentes, feos, desarreglados y en situaciones de consumo o venta de drogas. Las burlas también se dirigen a aspectos académicos, como el perfil vocacional, los bajos niveles de rendimiento y exigencia, y las deficiencias en infraestructura y recursos pedagógicos. Las imágenes que predominan asocian a los estudiantes de estas escuelas vocacionales con cierto tipo de comportamientos considerados "desviados" o entendidos como rasgos culturales propios de las clases desfavorecidas — promiscuidad, suciedad, adicciones-

Entrevistador: A ver, cuéntenme un poco, recién decían: “¡no, Conalep, no!”. ¿Qué es lo que se dice de los Conalep?
Gina: Se dice del Conalep que normalmente las chavas que vamos aquí salimos embarazadas, que no acabamos la prepa, que aquí es mucho desastre [...], o sea, se habla muy mal del Conalep, principalmente por las chavas embarazadas, principalmente es el sello que tiene el Conalep.

Brenda: Y luego, como hacen sus memes, dicen que aquí nadie sale aquí virgen [risas] (Gina, 15 años de edad; Brenda, 17 años de edad; bachillerato técnico, grupo focal GF-A01).

Ser conscientes de estos estigmas tiene implicaciones sobre la subjetividad. Como observa Goffman (1970), los individuos estigmatizados con frecuencia deben asumir la responsabilidad de la interacción 
para evitar el malestar, el disgusto o la incomodidad en otros, dado que socialmente se considera que los rasgos estigmatizadores se deben a fallas del sujeto. $\mathrm{Al}$ mismo tiempo, esto provoca que el sujeto estigmatizado despliegue diversas estrategias para preservar su propio sentido de autovaloración:

Nunca me dejé guiar por ese estereotipo de que los Conalep siempre iban a ser bajos, siempre... Incluso hacen memes de los Conalep, de la Britny y el Brayan y que somos los que asaltan. ¡Ay! Así como que somos la categoría más baja, pero yo nunca me quise guiar con ese estereotipo. Dije: "pues hasta que lo vea, hasta que lo compruebe voy a hacerle caso", y cuando vine aquí no, no, muchas personas son muy tranquilas, muy amables, muy solidarias, más que nada eso (Lucy, 15 años de edad, bachillerato técnico, entrevista E-A01).

Ante la desvalorización y descalificación social, las clases subalternas pueden desarrollar estrategias de revalorización de lo propio (Reygadas, 2015). De esta manera, a la par que se protege la autoestima, se resiste y disputa la hegemonía de los discursos estigmatizadores. Es decir, la desigualdad en las relaciones de poder no significa que estos procesos simbólicos sean unidireccionales. Las clases subalternas ponen en juego formas de resistencia frente a las prácticas discursivas que los construyen como los otros inferiores (Lamont y Mizrachi, 2012; Skeggs, 2004).

Varios de los estudiantes entrevistados, incluso algunos profesores, despliegan herramientas retóricas o hacen una inversión simbólica de ciertos valores que responden a la estigmatización, el racismo y la discriminación. En congruencia con hallazgos previos de investigaciones similares (Reay, 2007; 2017), observamos que estos jóvenes procuran desafiar las imágenes negativas de sus escuelas al matizar esas mismas imágenes, o bien, al focalizar la atención sobre otros valores propios:
Gaby (G): Igual de todos los compañeros o ex compañeros que tengo. Cuando se enteran, dicen: “jay! ¡Te quedaste en un Conalep!”. Y ésa es la mala imagen que tiene un Conalep.

Entrevistador: ¿Ah, sí? ¿Por qué?

G: Ah, porque todos dicen que un Conalep no, que puro mariguano o que las chavas salen embarazadas y todo eso. Pero una vez me molestó que un compañero me dijo: "no, que ahí del Conalep salen todas embarazadas”, y no sé qué más y qué tanto, entonces el comentario que yo le hice fue: “ojalá que ningún día”. ¡Ah! Que los del Conalep eran todos vagos, algo así me dio a entender. Entonces le dije: "ojalá en ningún momento de tu vida te toque llegar a un hospital y te toque que un vago del Conalep te atienda y te llegue a salvar tu vida por hacer prácticas o porque ese vago sabe hacer lo que tal vez tú no" (Gaby, 15 años de edad, bachillerato técnico, entrevista E-A02).

Sí, de hecho, sí me ha tocado ver que hacen como que burlas de Conalep o de cBTIs [Centro de Bachillerato Tecnológico Industrial y de Servicios] y yo digo, a final de cuentas, la escuela no es como que te haga a ti, ¿no? Tú haces a la escuela y por ti la escuela está. Pero a mí sí me molesta en el sentido de que dicen: "nooo, en el Conalep son unos burros, en el Conalep no saben, en el Conalep los maestros son malos, salen embarazadas", y que no sé qué. Y, o sea, sí, salen embarazadas, pero en todos lados salen embarazadas, aun en las mejores escuelas. También digo: "no, no son malos maestros". Yo ahora sí les puedo decir. Yo antes escuchaba que se burlaban y les decía: "ya cállense, si no saben” o "¿acaso ya han pasado por ahí?”. "No". "Entonces, si no sabes, no digas", ¿no? Pero ya ahorita que lo estoy experimentando, puedo decir y puedo justificar que Conalep sí sabe, que Conalep sí tiene buenos maestros, y en todos lados puede haber buenos o malos maestros y es lo que digo: "no se pasen, no digan así" (Sofía, 18 años de edad, bachillerato técnico, entrevista E-A10). 
Estos testimonios muestran algunas de las estrategias retóricas mediante las cuales se resignifican o reenmarcan los estereotipos negativos: "en sus escuelas, como en otras, hay malos y buenos profesores", "las estudiantes se embarazan como en otras escuelas", "las escuelas técnicas tienen mala fama, pero depende de su especialidad o de la localización". Estos matices permiten desafiar las imágenes negativas homogeneizadoras de sus escuelas y recuperan espacios locales y experiencias personales en los que se entrelazan rasgos positivos y negativos. Además, se ejerce una (re)valorización social de lo propio, como "la solidaridad de los compañeros" o "el orgullo y la dignidad de tener una formación profesional que salva vidas". En este caso, lo que se disputa y combate es la representación pública de sus lugares y experiencias.

El espacio local, en este caso la escuela, y la interacción cotidiana suelen ser los sitios en los que el estigma es resistido. Sin embargo, es oportuno destacar, siguiendo a Skeggs (1997), que la habilidad de los sujetos estigmatizados para contrarrestar la descalificación de su capital cultural no significa que logren revalorarlo. Más bien, estas tácticas representan rechazos y resistencias coyunturales de los más desfavorecidos.

\section{LA DISCIPLINA ESCOLAR: ENTRE EL TEMOR Y LA PRETENSIÓN DE REFORMAR}

La disciplina escolar es un tema que adquiere relevancia particular en las escuelas a las que asisten los sectores populares y más desfavorecidos, ya que la opinión pública suele caracterizarlas como espacios de indisciplina, desorden e incluso violencia. Reay (2007), por ejemplo, se refiere a la estigmatización de estas instituciones como "espacios ingobernables". Esta percepción de ingobernabilidad hace que la disciplina adquiera centralidad tanto en su dimensión instrumental, para hacer posible la práctica de aprendizaje, como en la performativa, para formar un carácter en los estudiantes. Como señala Rodríguez (2016), en estas escuelas parece que la prioridad es la disciplina escolar por encima del acompañamiento de sus alumnos.

Durante el trabajo de campo, un maestro comentaba que en su escuela, a diferencia de otras, "los alumnos no tienen esa disciplina [...], nuestros alumnos egresados de aquí no tienen disciplina: van a un trabajo y van a actuar igual que aquí, 'namás que me paguen' y ‘[hago] lo mínimo para que me paguen y ya"” (Luis, profesor de psicología, bachillerato técnico, entrevista E-A14). Esta reducción de la "indisciplina" como rasgo propio de los sectores populares genera un entorno de vigilancia permanente, en el que el orden, el control y la supervisión de los estudiantes comienzan desde la puerta de entrada:

Aquí siempre está el primer filtro, que es la entrada. Pero ya entrando aquí, se vuelven a deschongar [las niñas] y todo el rollo. Entonces, todos los maestros tenemos esa tarea o consigna, de si vemos a alguien: "oye, ponte tu uniforme, ponte la filipina, péinate, bla, bla, bla", pero hay unos que sí, no entienden. Entonces, cuando pasan esas situaciones, se mandan a orientación, y orientación hace que vengan los padres. Ha habido infinidad de anécdotas en esa acción: "es que la muchacha", y viene la mamá y está peor, ¡que tatuada...! ¡No! "Es que trae un peinado muy estrafalario, con luces y cabello rojo”, y llega la mamá y está todavía más exagerado. Entonces, es donde te das cuenta que ellos están acostumbrados, por su ambiente socioeconómico, por su familia. No hay ese respeto, simplemente (Marcos, profesor de matemáticas, bachillerato técnico, entrevista E-A12).

Los comportamientos o disposiciones que requieren disciplina varían y corresponden a ámbitos diversos, pero en general se vinculan al origen social 
de los estudiantes. Maestros y autoridades, incluso los alumnos, asocian las normas establecidas y su rigidez con la búsqueda de las condiciones mínimas necesarias para dar clases, como cumplir los horarios o mantenerse en silencio, pero también con la pretensión de "cultivar" en estos jóvenes actitudes y hábitos de los que carecen y que necesitarán en otros espacios de la vida. Nancy asociaba la disciplina a ciertos valores: "creo que a mí, en lo personal, me ayudó, y creo que a los alumnos también les ayuda esta situación de fomentar valores que nos dan ciertos elementos de disciplina, como llegar puntuales, aprender a traer un uniforme o participar en eventos cívicos, etc." (Nancy, profesora de inglés, bachillerato general, entrevista E-B16).

La asociación de los ejemplos denota el carácter doble de la disciplina. "Aprender a traer uniforme" y "participar en eventos cívicos" no parecen cumplir ningún papel instrumental relevante, más bien representan mecanismos que transmiten un mensaje moral con el cual se pretende suscitar el desarrollo o transformación - moral- de los estudiantes (Kulkarni, 2017). Esta pretensión, por ejemplo, es reconocida por uno de los maestros entrevistados: "la mayoría los ve y los descalifica, que son apáticos, que no se arreglan bien, que no tienen dinero. Y yo me identifico, yo soy así, yo era así, entonces mi anhelo es formarlos o reformarlos" (Luis, profesor de psicología, bachillerato técnico, entrevista E-A14).

Esta dimensión performativa de la disciplina encuentra fundamento en las representaciones públicas dominantes que descalifican a las clases desfavorecidas y atribuyen a los pobres una condición cultural y moral disfuncional como causa principal de sus dificultades para una integración exitosa a la sociedad. De allí que en muchos casos los maestros y autoridades escolares asuman la tarea de disciplinar como una de sus mayores responsabilidades para dar orden a esas vidas caóticas, como señala Ladson-Billings (2017). En el fondo, como en el caso de Luis, hay una franca expectativa de que ello contribuya a mejorar sus posibilidades de integración.

Algunos de los profesores entrevistados asocian los problemas de disciplina, y la centralidad que adquiere en sus escuelas, a la condición de clase de los estudiantes. Si bien consideran que sus comportamientos y costumbres se deben a las condiciones estructurales de desventaja en las que viven, destacan las dimensiones morales en relación con la condición de clase:

De los chavos, la primera es que no les gusta [la escuela], o sea, no es la opción que ellos querían. La segunda, son las condiciones socioeconómicas en las que ellos viven, ése es un tema también importante, o sea, a veces, tú llegas al chavo y se está durmiendo y ello es una falta de respeto, ¿no? “¿Qué sucede contigo?". "No, profe, es que en la noche mis papás discutieron" o "mi papá llegó muy tarde borracho y pues no pude..." o "cuando llegamos a la casa ya habían sacado nuestras cosas [por desalojo]" (Marcos, profesor de matemáticas, bachillerato técnico, entrevista E-A12).

Ahora la disciplina es: "no digas groserías" y... [porque] las malas palabras es el orden del día. Dice uno: “a mí me arrullaban mentándome la mamá”, pues sí, eso me imagino. Yo digo, en el interior: "iclaro! Pues por eso lo repites". Pero, a ver, si vamos a cambiar a un paciente no le puedes hablar así, [pero] no sé si lo logren, yo creo que no (Rosaura, profesora, bachillerato técnico, entrevista E-A16).

En ambas escuelas, la supervisión y el control riguroso del uniforme, y en términos más generales, de las normas y sanciones relativas a la vestimenta y presentación de los estudiantes, aparece como un hecho paradigmático en el que se sintetiza la dimensión moralizadora de la disciplina escolar en los sectores populares. El uniforme y la presentación personal se conciben como instrumentos cuyo único o 
principal objetivo es incidir en la moralidad de los adolescentes. Esto es evidente en el discurso de los maestros y autoridades, quienes, más allá de algunos motivos de seguridad e identidad, reconocen de manera explícita que la prohibición de pintarse el pelo de colores fuertes, usar aretes o perforaciones, o una sudadera diferente, nada tiene que ver con el aprendizaje de los estudiantes. El uniforme se concibe como una especie de "etiqueta" positiva que denota ciertas cualidades morales de la persona que lo porta. De esta manera, la normatividad sobre la presentación de los alumnos y su cumplimiento estricto adquieren un carácter pedagógico sobre la moralidad de las clases subalternas:

Se ha hecho una campaña en redes sociales, en televisión, en medios masivos y entonces ya hay como más apertura; sin embargo, me encuentro en el aeropuerto y me encuentro con una solicitud, un cartel de "se busca personal para trabajar" de Burger King de México, pero "piercings no visibles, tatuajes no visibles, preparatoria con promedio mínimo de 8, conocimientos elementales de inglés". Entonces uno pregunta: "bueno, si hay toda esta apertura, ¿por qué me encuentro con esta situación contradictoria?". Hay esta apertura hacia "sí, tatúate, sí, no hay problema, yo te acepto", pero en una situación laboral, que es a lo que mis alumnos se van a enfrentar, existe esta acción discriminatoria, y cuando uno va a ver la legalidad, resulta que como es una empresa de atención al público y las estadísticas marcan que los piercings y los tatuajes generan un cierto nivel de incomodidad en el cliente, entonces se reservan el derecho de contratar (Nancy, profesora de inglés, bachillerato general, entrevista E-B16).

Lo que la institución avizora como destino laboral de estos adolescentes tiene un fuerte efecto en la disciplina. Lejos de concebirla como un espacio de libertad a partir del cual construir una sociedad más respetuosa y abierta a la diferencia y la diversidad, la escuela asume y reproduce los estigmas sociales, y prepara a sus estudiantes para lidiar con ellos desde su condición de clase, es decir, desde la aceptación y la subordinación. Lo anterior se articula con dos principios en apariencia contradictorios del neoliberalismo, a los que se refiere Dean (2018: 37): el de que el Estado debe retroceder o retirarse en nombre de la libertad individual, que coexiste con la desconfianza hacia los sujetos que no se consideran suficientemente capaces o responsables para usar esa libertad, por lo que reciben un tratamiento de tipo paternalista, autoritario y coercitivo para que adopten ciertas formas de subjetividad funcionales para la vida social y económica contemporánea.

\section{Conclusiones}

Las reflexiones y el análisis que desarrollamos en este artículo pretenden llamar la atención acerca de la relevancia de algunas dimensiones clave y poco exploradas de la desigualdad que, en términos de Therborn (2015), corresponden al ámbito de la desigualdad existencial. Si bien hay una relación recíproca entre la desigualdad existencial y la de recursos y oportunidades, la cual es determinante, nos interesa resaltar que las disparidades en las condiciones de vida, incluso el bienestar, no se agotan en los niveles de ingreso, educación o capital social. Las dimensiones simbólicas tienen implicaciones profundas en la experiencia social y subjetiva de la desigualdad, así como en su reproducción y legitimación.

El discurso meritocrático que permea el sistema educativo es un poderoso mecanismo de legitimación de las desigualdades y de imputación de responsabilidad individual sobre éstas. Como establecieron los enfoques reproduccionistas, las desigualdades extraescolares - económicas, sociales y culturales, hasta institucionales- que condicionan el desempeño y los resultados académicos son desdibujadas por un discurso meritocrático escolar que 


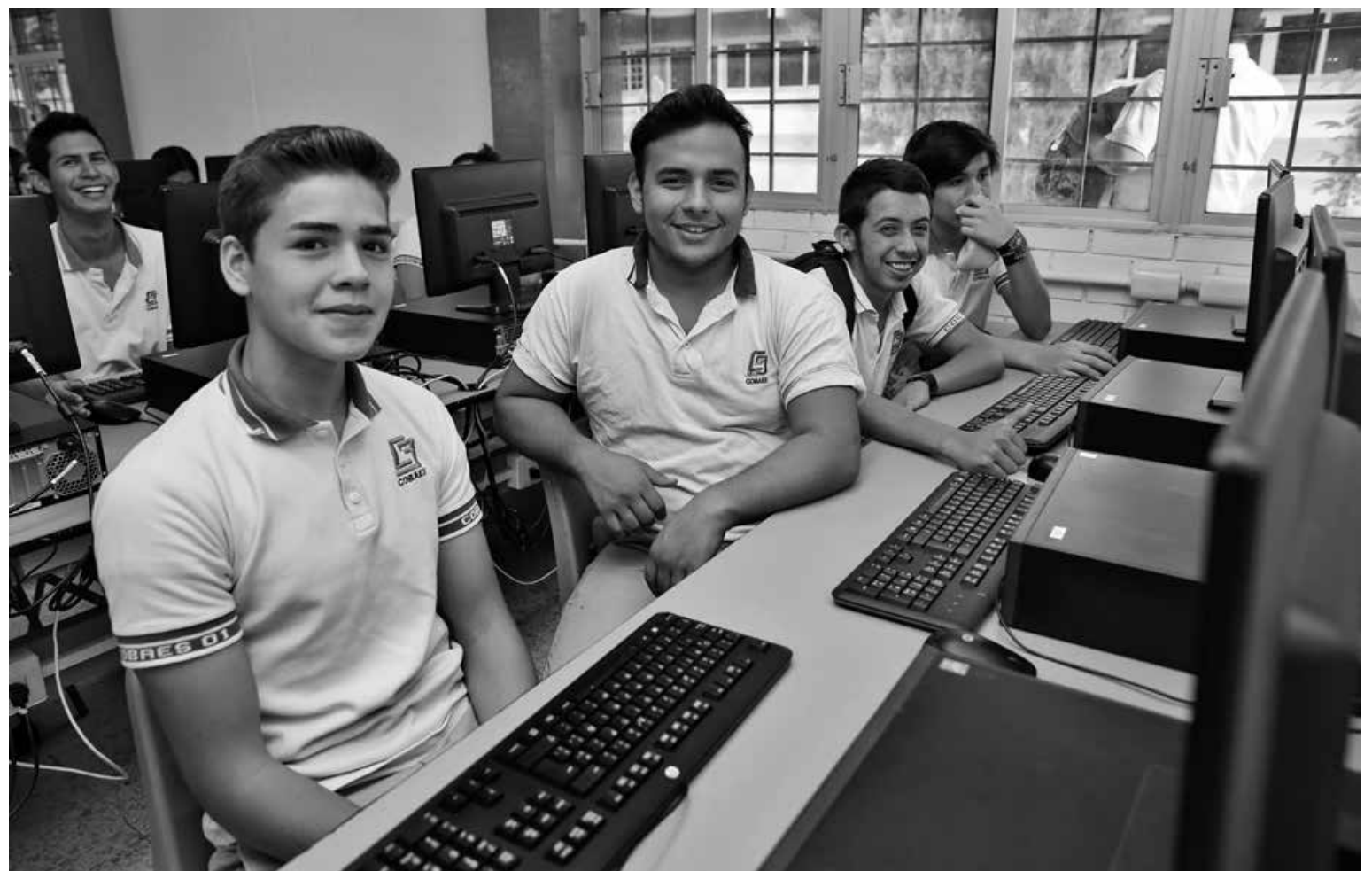

Gobierno deL ESTADo de SINALOA • Inauguración del ciclo escolar 2015-2016 del Colegio de Bachilleres del Estado de Sinaloa, agosto de 2015.

las abstrae y privilegia el esfuerzo y las cualidades personales. El resultado es que el paso por la escuela transforma las desigualdades estructurales en desigualdades justas o legítimas (Dubet, 2015). Al mismo tiempo, este proceso alimenta la construcción de estigmas y otras imágenes que infravaloran a los sectores más desfavorecidos. El desempeño escolar deficiente de los jóvenes de las clases bajas, sus dificultades para ingresar a ciertas escuelas y sus opciones laborales posteriores, escasas y precarias, se atribuyen a fallas o carencias personales.

El mayor acceso de los sectores populares al sistema educativo representa un avance social notorio e innegable en el campo de la igualdad de oportunidades. Sin embargo, no significa que se disipen las desigualdades de clase en la experiencia escolar. La masificación y el ingreso paulatino de los sectores populares a niveles educativos más altos han favorecido una diferenciación creciente en el prestigio y valoración social de las escuelas. Así, mientras las instituciones de los sectores privilegiados gozan de prestigio social, las de los sectores más desfavorecidos, al igual que sus trayectorias educativas, suelen estar marcadas por la estigmatización y la desvalorización, en muchos casos asociadas a significados morales atribuidos a su condición de clase. Estas dimensiones simbólicas establecen una jerarquía social que, a la par de legitimar la desigualdad de recursos, la reproduce. Además, influyen en las relaciones sociales, las expectativas recíprocas, muchas de sus prácticas cotidianas y la autoestima de estos jóvenes, y contribuyen a una integración jerarquizada y desfavorable.

Los procesos de clasificación social no sólo tienen un carácter descriptivo, también inciden en el mundo social que describen. Las interacciones y 
expectativas recíprocas entre miembros de grupos diferentes, por ejemplo, están pautadas por estas representaciones. Lo mismo sucede con los procesos de subjetivación, condicionados por la forma en que somos vistos por los "otros" y por el lugar que ocupamos en el mundo social. Como observa Di Napoli, con base en Bourdieu, "las clasificaciones o etiquetamientos de los estudiantes son actos productivos que tienen efecto de verdad sobre las experiencias de subjetivación propias" (2013: 45). Durante el trabajo de campo, las entrevistas con maestros mostraron que con frecuencia las etiquetas o clasificaciones que asignan a sus estudiantes se ligan de manera directa a su condición de clase. Las imágenes, estereotipos y juicios que socialmente se atribuyen a las clases subalternas se trasladan y encarnan en sujetos individuales. Así, la interacción y las expectativas en torno a estos jóvenes, sus propias respuestas e identidades, están permeadas desde el comienzo por los atributos morales asociados a su condición de clase. Su incidencia en el proceso de subjetivación tiene un nuevo efecto de disciplina.

Los sectores desfavorecidos, sin embargo, no son sujetos pasivos frente a la violencia simbólica ejercida por medio de la estigmatización y la desvalorización. Al mismo tiempo que reconocen los estereotipos y prejuicios que pesan sobre ellos, los estudiantes de estas escuelas socialmente devaluadas desarrollan formas de resistencia, ya sea al establecer matices de lugar o experiencias personales contrarias, o bien al destacar acciones, actitudes o valores propios que cuestionan la descalificación y falta de valoración social de las que son objeto. Nuestro análisis previo sugiere que para identificar y entender cómo los jóvenes de sectores populares resignifican y reenmarcan el estigma, es necesario escuchar qué tienen que decir sobre sí mismos y acercar sus percepciones y experiencias, con las cuales desafían las imágenes monolíticas y hegemónicas, a espacios más localizados de representación. Los grupos en desventaja, en relaciones de desigualdad, pueden criticar las categorías hegemónicas o traspasar y ridiculizar las categorías y bordes que los separan. Pero estas prácticas de resistencia demandan del investigador un esfuerzo de desclasificación que supone explorar y entender los modos mediante los cuales los sujetos estigmatizados logran activar valores alternativos para desviar y combatir los estigmas de clase que pesan sobre ellos y sus lugares.

A pesar de todo, desafiar el desprecio y la devaluación personal no supone que los sujetos subalternos se muevan a posiciones de poder. Significa, simplemente, rechazar la devaluación e inferiorización cotidianas, en un esfuerzo que les permita seguir adelante en una sociedad profundamente desigual. La reducción de la desigualdad demanda tanto reconocimiento como redistribución; no basta con modificar o eliminar las creencias y actitudes discriminatorias, es necesario transformar las estructuras institucionales que organizan la distribución desigual de recursos y oportunidades sobre las que se asientan, reproducen y legitiman. $\mathbb{D}$

\section{Bibliografía}

Aguilar Nery, Jesús, 2013, “Enfoques epistemológicos de la investigación sobre desigualdades educativas en México, 1970-2010”, en Revista Mexicana de Investigación Educativa, vol. 18, núm. 59, pp. 1077-1101.

Álvarez Rivadulla, María José, 2014, “Tolerancia a la desigualdad en América Latina: una exploración en Montevideo y Bogotá”, en Ensambles, núm. 1, pp. 99-119.

Backhoff, Eduardo, Arturo Bouzas, Eduardo Hernández y Marisela García, 2007, Aprendizaje y desigualdad social en México, Instituto Nacional para la Evaluación de la Educación, México. 
Ball, Stephen, Jackie Davies, Miriam David y Diane Reay, 2002, '“Classification' and 'Judgement': Social Class and the 'Cognitive Structures' of Choice of Higher Education", en British Journal of Sociology of Education, vol. 23, núm. 1, pp. 51-72.

Bayón, María Cristina, 2009, "Persistencia de un modelo social excluyente en México", en Revista Internacional del Trabajo, vol. 128, núm. 3, pp. 331-347.

—_ 2015, La integración excluyente. Experiencias, discursos y representaciones de la pobreza urbana en México, Universidad Nacional Autónoma de México-Instituto de Investigaciones Sociales/Bonilla Artigas Editores, México.

Bhabha, Homi, 1983, "The Other Question... Homi K. Bhabha Reconsiders the Stereotype and Colonial Discourse”, en Screen, vol. 24, núm. 6, pp. 18-36.

Blanco, Emilio, 2011, Los límites de la escuela en México. Educación, desigualdad y aprendizajes en México, El Colegio de México, México.

, 2014, "La desigualdad social en el nivel medio superior de educación de la Ciudad de México", en Papeles de Población, vol. 20, núm. 80, pp. 249-280.

Blanco, Emilio, Patricio Solís y Héctor Robles (coords.), 2014, Caminos desiguales. Trayectorias educativas y laborales de los jóvenes en la Ciudad de México, El Colegio de México/Instituto Nacional para la Evaluación de la Educación, México.

Bourdieu, Pierre, 2002 [1979], La distinción. Criterio y bases sociales del gusto, Taurus, México.

Cárdenas Denham, Sergio, 2011, “Escuelas de doble turno en México: una estimación de diferencias asociadas con su implementación”, en Revista Mexicana de Investigación Educativa, vol. 16, núm. 50, pp. 801-827.

Comisión Económica para América Latina y el Caribe (CEPAL), 2017, Panorama social de América Latina 2016, Naciones Unidas, Santiago.

Consejo Nacional de Evaluación de la Política de Desarrollo Social (Coneval), 2014, Pobreza y derechos sociales de niñas, niños y adolescentes en México, 2014, Consejo Nacional de Evaluación de la Política de Desarrollo Social/Fondo de las Naciones Unidas para la Infancia, México.

Dean, Mitchell, 2018, “The Secret Life of Neoliberal Subjectivity”, en Sanford Schram y Marianna Pavlovskaya (eds.), Rethinking Neoliberalism. Resisting the Disciplinary Regime, Routledge, Nueva York, pp. 23-40.

Dubet, François, 2015, ¿PPor qué preferimos la desigualdad?, Siglo XXI Editores, Buenos Aires.

Goffman, Erving, 1970, Estigma. La identidad deteriorada, Amorrortu, Buenos Aires.

Guzmán Gómez, Carlota, 2012, “Quedar afuera: experiencias y vivencias de los jóvenes que no logran ingresar a la universidad”, en Cultura y Representaciones Sociales, vol. 6, núm. 12, pp. 131-164.

Guzmán Gómez, Carlota y Claudia Saucedo Ramos (coords.), 2015, Revista Mexicana de Investigación Educativa, vol. 20, núm. 67: Experiencias y sentidos de la escuela desde la perspectiva estudiantil.

Instituto Nacional para la Evaluación Educativa (INEE), 2016, La educación obligatoria en México. Informe 2016, Instituto Nacional para la Evaluación Educativa, México.

Kulkarni, Vani S., 2017, “The Fight: Discipline and Race in an Inner-City Public Charter High School”, en The Annals of the American Academy of Political and Social Science, vol. 673, núm. 1, pp. 150-168.

Ladson-Billings, Gloria, 2017, "'Makes me Wanna Holler': Refuting The 'Culture of Poverty' Discourse in Urban Schooling”, The Annals of the American Academy of Political and Social Science, vol. 673, núm. 1, pp. 80-90.

Lamont, Michèle y Nissim Mizrachi, 2012, "Ordinary People Doing Extraordinary Things: Responses to Stigmatization in Comparative Perspective”, en Ethnic and Racial Studies, vol. 35, núm. 3, pp. 365-381.

Lamont, Michèle y Virág Molnár, 2002, "The Study of Boundaries in the Social Sciences”, en Annual Review of Sociology, vol. 28, pp. 167-195. Lübker, Malte, 2004, “Globalization and Perceptions of Social Inequality”, en International Labour Review, vol. 143, núms. 1-2, pp. 91-128.

Napoli, Pablo di, 2013, "Violencia, racismo y escuela. El caso de los alumnos tipificados como violentos", en Propuesta Educativa, núm. 39 , pp. 43-50.

Reay, Diane, 2007, “Unruly Places': Inner-City Comprehensives, Middles-Class Imaginaries and Working-Class Children”, en Urban Studies, vol. 44, núm. 7, pp. 1191-1201.

- 2017, Miseducation: Inequality, Education and the Working Classes, Policy Press, Bristol.

Reygadas, Luis, 2015, "The Symbolic Dimension of Inequalities”, documento de trabajo 78, desiguALdades.net-International Research Network on Interdependent Inequalities in Latin America, Berlín. Disponible en línea: <http://www.desigualdades.net/Working_ Papers/Search-Working-Papers/working-paper-78-_the-symbolic-dimension-of-inequalities_/index.html>.

Rodríguez Rocha, Eduardo, 2016, "El rol de la escuela en las decisiones educativas de sus alumnos bajo el contexto de la transición a las instituciones públicas de educación media superior de la Ciudad de México”, en Estudios Sociológicos, vol. 34, núm. 102, pp. 639-664. 
Saraví, Gonzalo A., 2015, Juventudes fragmentadas, Facultad Latinoamericana de Ciencias Sociales-México/Centro de Investigaciones y Estudios Superiores en Antropología Sociales, México.

Sayer, Andrew, 2005, The Moral Significance of Class, Cambridge University Press, Nueva York.

2015, Why we Can't Afford the Rich, Policy Press, Bristol.

Sibley, David, 1995, Geographies of Exclusion, Routledge, Londres.

Skeggs, Beverley, 1997, Formations of Class and Gender. Becoming Respectable, Sage Publications, Londres.

, 2004, Class, Self, and Culture, Routledge, Londres.

Solís, Patricio, Eduardo Rodríguez Rocha y Nicolás Brunet, 2013, "Orígenes sociales, instituciones y decisiones educativas en la transición a la

educación media superior. El caso del Distrito Federal”, en Revista Mexicana de Investigación Educativa, vol. 18, núm. 59 , pp. 1103 -1136.

Therborn, Göran, 2015, Los campos de exterminio de la desigualdad, Fondo de Cultura Económica, Buenos Aires.

Tilly, Charles, 2000, La desigualdad persistente, Manantial, Buenos Aires.

Tyler, Imogen, 2013, Revolting Subjects. Social Abjection and Resistance in Neoliberal Britain, Zed, Londres.

Watt, Paul, 2006, "Respectability, Roughness and 'Race': Neighbourhood Place Images and the Making of Working-Class Social Distinctions in London", en International Journal of Urban and Regional Research, vol. 30, núm. 4, pp. 776-797.

Weiss, Eduardo (coord.), 2012, Jóvenes y bachillerato, Asociación Nacional de Universidades e Instituciones de Educación Superior, México.

\section{Entrevistas}

Brenda, 17 años de edad, bachillerato técnico, grupo focal GF-A01.

Edu, 15 años de edad, bachillerato general, grupo focal GF-B01.

Franco, 16 años de edad, bachillerato general, grupo focal GF-BO1.

Gaby, 15 años de edad, bachillerato técnico, entrevista E-A02.

Gina, 15 años de edad, bachillerato técnico, grupo focal GF-A01.

Lola, 16 años de edad, bachillerato general, grupo focal GF-BO1.

Lucy, 15 años de edad, bachillerato técnico, entrevista E-A01.

Luis, 15 años de edad, bachillerato técnico, entrevista E-A08.

Luis, profesor de psicología, bachillerato técnico, entrevista E-A14.

Marcos, profesor de matemáticas, bachillerato técnico, entrevista E-A12.

Nancy, profesora de inglés, bachillerato general, entrevista E-B16.

Perla, 16 años de edad, bachillerato general, grupo focal GF-B01.

Rosaura, profesora, bachillerato técnico, entrevista E-A16.

Sofía, 18 años de edad, bachillerato técnico, entrevista E-A10.

Zule, 15 años de edad, bachillerato general, grupo focal GF-B01. 